\title{
Article \\ Pyuria as a Predictive Marker of Bacillus Calmette-Guérin Unresponsiveness in Non-Muscle Invasive Bladder Cancer
}

\author{
Jungyo Suh ${ }^{1}{ }^{(}$, , Hyeong Dong Yuk $^{2}{ }^{\circledR}$, Chang Wook Jeong ${ }^{2,3}{ }^{\circledR}$, Cheol Kwak ${ }^{2,3}$, Hyeon Hoe Kim ${ }^{2,3}$ \\ and Ja Hyeon $\mathrm{Ku}^{2,3, *}$ \\ 1 Department of Urology, Asan Medical Centre, Seoul 05505, Korea; uro_jun@amc.seoul.kr \\ 2 Department of Urology, Seoul National University Hospital, Seoul 03080, Korea; armenia8@snu.ac.kr (H.D.Y.); \\ drboss@snu.ac.kr (C.W.J.); mdrafael@snu.ac.kr (C.K.); hhkim@snu.ac.kr (H.H.K.) \\ 3 Department of Urology, Seoul National University College of Medicine, Seoul 03080, Korea \\ * Correspondence: kuuro70@snu.ac.kr; Tel.: +82-2-2072-2428; Fax: +82-2-742-4665
}

Citation: Suh, J.; Yuk, H.D.; Jeong, C.W.; Kwak, C.; Kim, H.H.; $\mathrm{Ku}$, J.H. Pyuria as a Predictive Marker of Bacillus Calmette-Guérin Unresponsiveness in Non-Muscle Invasive Bladder Cancer. J. Clin. Med. 2021, 10, 3764. https://doi.org/ $10.3390 / \mathrm{jcm} 10173764$

Academic Editor: Frank Friedersdorff

Received: 7 June 2021

Accepted: 19 August 2021

Published: 24 August 2021

Publisher's Note: MDPI stays neutral with regard to jurisdictional claims in published maps and institutional affiliations.

Copyright: (c) 2021 by the authors. Licensee MDPI, Basel, Switzerland. This article is an open access article distributed under the terms and conditions of the Creative Commons Attribution (CC BY) license (https:// creativecommons.org/licenses/by/ $4.0 /)$.

\begin{abstract}
This study aims to investigate the clinical role of preoperative pyuria for predicting bacillus Calmette-Guérin (BCG) unresponsiveness in non-muscle invasive bladder cancer (NMIBC). We performed a logistic regression analysis on 453 patients with NMIBC who were treated with BCG immunotherapy after a transurethral resection of bladder tumours, to evaluate predictive factors of BCG unresponsiveness. We also analysed univariate and multivariable survival data to estimate the prognostic impact of pyuria. Of the total study population, 37.6\% (170/453) of patients had BCG unresponsiveness. A multivariable logistic regression analysis revealed that a history of upper urinary tract cancer (odds ratio (OR): $1.86,95 \%$ confidence interval $(\mathrm{CI}): 1.04-3.32, p$-value $=0.035$ ) and the presence of pyuria (OR: $1.51,95 \% \mathrm{CI}: 1.01-2.27, p=0.047)$ and tumour multiplicity (OR: 1.80, 95\% CI: $1.18-2.75, p$-value < 0.001) were significant predictors of BCG unresponsiveness. A Cox proportional hazards analysis model showed that pyuria was a significant prognostic factor for progression-free survival (hazard ratio: $4.51,95 \% \mathrm{CI}: 1.22-16.66, p=0.024$ ). A history of upper urinary tract cancer and the presence of pyuria and tumour multiplicity are predictive markers of BCG unresponsiveness. For patients with NMIBC who have preoperative pyuria, treatment using BCG should be considered cautiously.
\end{abstract}

Keywords: pyuria; non-muscle invasive bladder cancer; BCG immunotherapy

\section{Introduction}

Bladder cancer is the 10th most common cancer worldwide and is highly prevalent in developed countries [1]. Up to $75 \%$ of patients with bladder cancer initially present with non-muscle invasive bladder cancer (NMIBC); however, $70 \%$ and $30 \%$ of patients with NMIBC experience recurrence and progression, respectively, within 5 years. Treatment with bacillus Calmette-Guérin (BCG) immunotherapy is recommended for patients with NMIBC, for whom there is an intermediate-to-high risk of recurrence or progression [2,3].

Although most patients with NMIBC initially respond to BCG immunotherapy, some experience recurrence or progression during or after treatment. 'BCG unresponsive' is a complex term that refers to a heterogeneous groups of patients for whom treatment with BCG immunotherapy is not recommended [4]. This term also describes patients in whom high-grade cancer persists even after they receive BCG treatment ('BCG refractory') and patients who experience recurrence after reaching a disease-free state ('BCG relapsing') within 6 months of their last BCG exposure [4]. The only recommended treatment for BCGunresponsive patients with NMIBC is radical cystectomy [2,3]. Despite their importance, predictors of BCG unresponsiveness have not been clearly investigated [5].

More than 40 years after its initial clinical application, the mechanism of BCG immunotherapy remains unclear. Current evidence suggests that a BCG-mediated local 
inflammatory response leads to a therapeutic effect [6]. Paradoxically, a tumour inflammatory response is itself known to be a poor prognostic marker for bladder cancer $[7,8]$. Recently, the clinical role of pyuria as a non-invasive biomarker for bladder cancer recurrence and progression was highlighted by a Japanese group [9]. In this study, we evaluated the predictive impact of preoperative pyuria on BCG unresponsiveness in intermediate-tohigh-risk NMIBC, using a prospectively collected dataset of the trans-urethral resection of bladder tumours (TURBT) cohort.

\section{Materials and Methods}

\subsection{Ethics Approval and Informed Consent}

This study was approved by the SNUH Institutional Review Board (SNUH IRB). Informed consent for the academic use of their clinical data was obtained from each patient at the time of their enrolment in the prospective registry (IRB No.: H-1506-122-682). For this ad hoc study, the SNUH IRB approved the academic use of registry data that focused on pyuria and BCG unresponsiveness, with respect to NMIBC that was treated with BCG (IRB No.: 2013-018-1202). All study processes were performed in accordance with relevant guidelines and regulations.

\subsection{Patient Selection and Cohort Follow-Up Protocols}

The Seoul National University Hospital Prospectively Enrolled Registry for Urothelial Carcinoma with Transurethral Resection of Bladder Tumor is a sub-cohort of a multidisciplinary, biobank-linked cohort of patients with genitourinary cancer in high-volume tertiary institutions [10]. Of 1557 patients with NMIBC who underwent TURBT between March 2016 and October 2020, the data from 453 patients treated with BCG-instillation therapy were collected for this analysis. To clarify the definition of 'BCG unresponsiveness', patients who received less than 6 months follow-up were excluded. Blood and urine laboratory tests were performed within 40 days of performing TURBT. All patients submitted a urine culture before TURBT. A patient displaying pyuria and febrile symptoms before TURBT was treated with antibiotics. All patients who had high-grade cancer during the initial TURBT underwent repeated TURBT within 1 month of the initial operation. NMIBC was confirmed after a review of the pathological specimens obtained from the initial or repeated TURBT, according to current guidelines [2,3].

BCG instillation and maintenance therapy were administered in accordance with the relevant guidelines. The BCG instillation protocol involved six cycles of weekly or biweekly induction and maintenance of BCG in tolerant patients. The maintenance schedule included intensive instillation every 3, 6 and 12 months in the first year and every 6 months for 2 additional years thereafter [11]. Cystoscopy and urine cytology were performed every 3 months to assess the recurrence of bladder cancer after any treatment cycle, including TURBT, and after induction and maintenance BCG. BCG unresponsiveness was defined as BCG refractory or BCG relapse with adequate BCG treatment [4]. Pyuria was defined as the presence of five or more white blood cells in a urine sample, as observed with a high-power field [12]. A tumour size of $>3 \mathrm{~cm}$ was considered a large tumour.

\subsection{Statistical Analyses}

All continuous variables are described as mean \pm standard deviation (interquartile range), whereas categorical variables are described as frequencies (percentages). Continuous variables were compared using Student's $t$-test, and categorical variables were compared using a chi-squared test or Fisher's exact test. Using univariate and multivariate logistic regression, we analysed the features associated with BCG unresponsiveness. The Kaplan-Meier curve and the log-rank test were used for a non-parametric comparison of RFS and PFS, relative to the presence of preoperative pyuria. For the multivariate analysis, the variables that showed a $p$-value of $<0.1$ in the univariate analysis were selected. Statistical analyses were performed using Python version 3.9.0, based on packages dependent 
on SciPy [13]. Statistical significance was set at $p<0.05$, and all reported $p$-values were two-sided.

\section{Results}

\subsection{Patient Characteristics}

Of the 1557 patients who underwent TURBT, 564 were treated with BCG immunotherapy. Finally, 453 patients who were treated with BCG immunotherapy after they had undergone TURBT at Seoul National University Hospital (SNUH) were analysed. A total of 174 patients had pyuria, and 262 patients had sterile urine before they underwent TURBT (Figure 1).

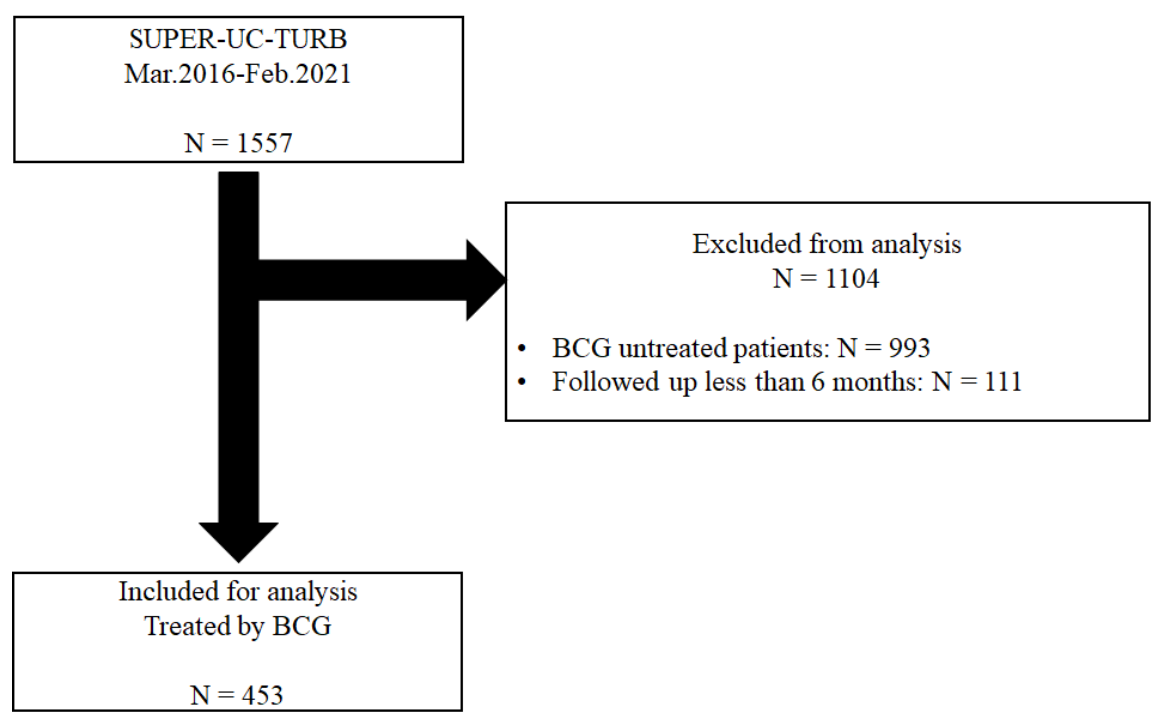

Figure 1. The flow chart of the inclusion and exclusion criteria and patient grouping based on the presence of pyuria before transurethral resection of the bladder.

Of the 453 patients, $37.6 \%$ (170/453) were BCG unresponsive during the $25.0 \pm 13.9$ months of the follow-up period. A history of previous upper urinary tract cancer (UTUC) (16.5\% vs. $9.9 \%, p=0.056)$, pyuria $(46.4 \%$ vs. $35.9 \%, p=0.039)$ and tumour multiplicity $(71.7 \%$ vs. $58.2 \%, p<0.001$ ) was significantly more prevalent in the BCG-unresponsive group than in the BCG-effective group (Table 1).

Table 1. Patient demographics of renal insufficiency and control groups.

\begin{tabular}{lccc}
\hline & BCG-Effective & BCG-Unresponsive & $p$-Value \\
\hline \multicolumn{1}{c}{ Number of Patients } & $N=\mathbf{2 8 3}$ & $\mathbf{1 7 0}$ & 0.629 \\
\hline Age, mean \pm SD (IQR) & $68.2 \pm 9.8(62.0-77.0)$ & $67.7 \pm 12.3(62.0-76.0)$ & $52(30.6)$ \\
\hline Previous TUR history, $n(\%)$ & $68(24.0)$ & $23(13.5)$ & 0.155 \\
\hline Female, $n(\%)$ & $41(14.5)$ & $20(11.8)$ & 0.885 \\
\hline Previous BCG treatment history, $n(\%)$ & $23(8.1)$ & $28(16.5)$ & 0.266 \\
\hline Upper Tract Urothelial Carcinoma history, $n(\%)$ & $28(9.9)$ & $95(57.2)$ & $77(46.4)$ \\
\hline Microscopic haematuria, $n(\%)$ & $143(52.8)$ & $7(4.1)$ & 0.056 \\
\hline Pyuria, $n(\%)$ & $97(35.9)$ & 0.418 \\
\hline BCG dose reduction, $n(\%)$ & $11(3.9)$ & 0.882 \\
\hline Pathologic T stage, $n(\%)$ & & $96(56.5)$ \\
\hline Ta & $162(57.2)$ & $74(43.5)$ \\
\hline T1 & $121(42.8)$ & 0.950 \\
\hline
\end{tabular}


Table 1. Cont.

\begin{tabular}{lccc}
\hline & BCG-Effective & BCG-Unresponsive & $p$-Value \\
\hline \multicolumn{1}{c}{ Number of Patients } & $N=\mathbf{2 8 3}$ & $N=\mathbf{1 7 0}$ & \\
\hline Tumour size $(>3 \mathrm{~cm}), n(\%)$ & $97(35.0)$ & $119(71.7)$ & 0.057 \\
\hline Multiple tumours, $n(\%)$ & $160(58.2)$ & $37(21.8)$ & $<0.001$ \\
\hline Concomitant CIS, $n(\%)$ & $63(22.3)$ & $7(4.1)$ & 0.995 \\
\hline Histologic variants, $n(\%)$ & $13(4.6)$ & 0.998 \\
\hline
\end{tabular}

\subsection{Univariate and Multivariate Logistic Regression for BCG Unresponsiveness}

Through univariate analysis, a history of UTUC (odds ratio (OR): $1.80,95 \%$ confidence interval (CI): $1.02-3.15, p=0.041$ ), the presence of pyuria (OR: 1.54, 95\% CI: 1.04-2.29, $p=0.031$ ), large tumour size (OR: $1.49,95 \%$ CI: $1.01-2.21, p=0.046)$ and the presence of multiple tumours (OR: $1.82,95 \%$ CI: $1.20-2.75, p=0.005$ ) were associated with BCG unresponsiveness. The multivariate analysis revealed that a history of UTUC (OR: 1.86, 95\% CI: $1.04-3.32, p=0.035$ ) and the presence of pyuria (OR: 1.51, 95\% CI: $1.01-2.27, p=0.047$ ) and multiple tumours (OR: 1.80, 95\% CI: 1.18-2.75, $p<0.001$ ) were significant predictors of BCG unresponsiveness (Table 2).

Table 2. Univariate and multivariable logistic regression for BCG unresponsiveness.

\begin{tabular}{|c|c|c|c|c|c|c|}
\hline \multirow[b]{2}{*}{ Variables } & \multicolumn{3}{|c|}{ Univariate } & \multicolumn{3}{|c|}{ Multivariable } \\
\hline & Odds Ratio & $\begin{array}{l}\text { Confidence } \\
\text { Interval }\end{array}$ & $p$-Value & Odds Ratio & $\begin{array}{c}\text { Confidence } \\
\text { Interval }\end{array}$ & $p$-Value \\
\hline Age & & & 0.799 & & & \\
\hline Age $<65$ & Ref. & & & & & \\
\hline $65 \leq$ Age $\leq 75$ & 0.89 & $0.51-1.54$ & & & & \\
\hline Age $>75$ & 1.02 & $0.60-1.74$ & & & & \\
\hline Previous TUR history & 1.39 & $0.91-2.13$ & 0.126 & & & \\
\hline Sex (Female) & 0.92 & $0.53-1.60$ & 0.777 & & & \\
\hline $\begin{array}{l}\text { Previous BCG treatment } \\
\text { history }\end{array}$ & 1.51 & $0.80-2.84$ & 0.203 & & & \\
\hline $\begin{array}{l}\text { Upper Tract Urothelial } \\
\text { Carcinoma history }\end{array}$ & 1.80 & $1.02-3.15$ & 0.041 & 1.86 & $1.04-3.32$ & 0.035 \\
\hline $\begin{array}{l}\text { BCG dose reduction } \\
\text { (half) }\end{array}$ & 1.05 & $0.40-2.76$ & 0.921 & & & \\
\hline Pathologic T stage (T1) & 1.03 & $0.70-1.51$ & 0.872 & & & \\
\hline Pyuria (more than W5) & 1.54 & $1.04-2.29$ & 0.031 & 1.51 & $1.01-2.27$ & 0.047 \\
\hline Large tumour $(3 \mathrm{~cm})$ & 1.49 & $1.01-2.21$ & 0.046 & 1.39 & & 0.136 \\
\hline Multiple tumour & 1.82 & $1.20-2.75$ & 0.005 & 1.80 & $1.18-2.75$ & $<0.001$ \\
\hline Concomitant CIS & 0.97 & $0.61-1.54$ & 0.902 & & & \\
\hline
\end{tabular}

3.3. Kaplan-Meier Curve with the Log-Rank Test for Recurrence- and Progression-Free Survival with or without Preoperative Pyuria in BCG-Treated Patients with Non-Muscle Invasive Bladder Cancer

In the sterile urine group, recurrence and progression occurred in $34.0 \%(89 / 262)$ and $1.5 \%(4 / 262)$ of patients, respectively. In the pyuria group, recurrence and progression were present in $44.3 \%(77 / 174)$ and 5.2\% (9/174) of patients, respectively. Estimated recurrencefree survival (RFS) in the pyuria group was significantly shorter than in the sterile urine group (33.74 \pm 2.07 months vs. $38.79 \pm 1.51$ months, respectively, $p=0.013$ ). The calculated 
progression-free survival (PFS) in the pyuria group was also significantly shorter than that in the sterile urine group (55.40 \pm 0.92 months vs. $56.70 \pm 0.40$ months, respectively, $p=0.025$ ) (Figure 2).
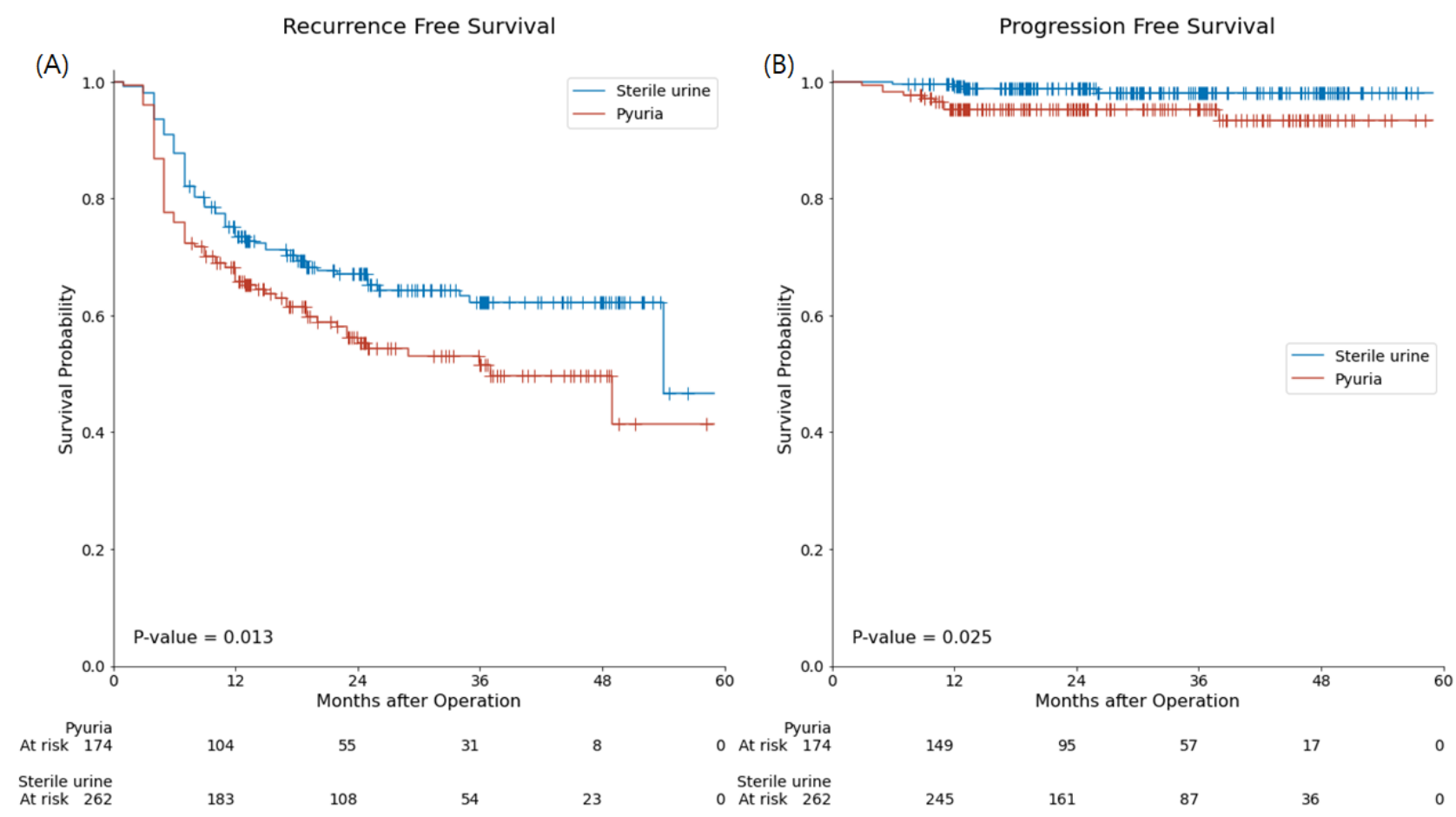

Figure 2. Kaplan-Meier curve and log-rank test for recurrence-free survival (A), and progression-free- survival (B) with or without preoperative pyuria in BCG-treated patients with non-muscle invasive bladder cancer. Redline and Blueline represent the pyuria group and sterile urine group, respectively.

\subsection{Univariate and Multivariate Analysis Using the Cox Proportional Hazards Regression Model}

Through the univariate analysis performed using the Cox proportional hazards regression model, with respect to RFS, the presence of pyuria (hazard ratio (HR): 1.47, 95\% (CI): 1.08-2.00, $p=0.013$ ), large tumour size (HR: 1.51, 95\% CI: 1.11-2.06, $p=0.009$ ) and the presence of multiple tumours (HR: $1.59,95 \%$ CI: 1.13-2.24, $p=0.008$ ) were found to be significant prognostic factors. Through the multivariate analysis performed using the Cox proportional hazards regression model, only the presence of multiple tumours was found to be a significant prognostic marker for RFS (HR: 1.51, 95\% CI: 1.07-2.15, $p=0.019$ ) (Table 3).

Table 3. Univariate and multivariable cox proportional hazards regression for recurrence-free survival.

\begin{tabular}{|c|c|c|c|c|c|c|}
\hline \multirow[b]{2}{*}{ Variables } & \multicolumn{3}{|c|}{ Univariate } & \multicolumn{3}{|c|}{ Multivariable } \\
\hline & Hazard Ratio & $\begin{array}{l}\text { Confidence } \\
\text { Interval }\end{array}$ & $p$-Value & Hazard Ratio & $\begin{array}{l}\text { Confidence } \\
\text { Interval }\end{array}$ & $p$-Value \\
\hline Age & & & 0.834 & & & \\
\hline Age $<65$ & Ref. & & & & & \\
\hline $65 \leq$ Age $\leq 75$ & 0.88 & $0.57-1.37$ & & & & \\
\hline Age $>75$ & 0.95 & $0.63-1.44$ & & & & \\
\hline Previous TUR history & 1.09 & $0.78-1.52$ & 0.614 & & & \\
\hline Sex (Female) & 0.94 & $0.60-1.48$ & 0.802 & & & \\
\hline $\begin{array}{l}\text { Previous BCG treatment } \\
\text { history }\end{array}$ & 1.22 & $0.76-1.94$ & 0.414 & & & \\
\hline
\end{tabular}


Table 3. Cont.

\begin{tabular}{|c|c|c|c|c|c|c|}
\hline \multirow[b]{2}{*}{ Variables } & \multicolumn{3}{|c|}{ Univariate } & \multicolumn{3}{|c|}{ Multivariable } \\
\hline & Hazard Ratio & $\begin{array}{l}\text { Confidence } \\
\text { Interval }\end{array}$ & $p$-Value & Hazard Ratio & $\begin{array}{l}\text { Confidence } \\
\text { Interval }\end{array}$ & $p$-Value \\
\hline $\begin{array}{l}\text { Upper Tract Urothelial } \\
\text { Carcinoma history }\end{array}$ & 1.36 & $0.92-2.04$ & 0.143 & & & \\
\hline $\begin{array}{l}\text { BCG dose reduction } \\
\text { (half) }\end{array}$ & 1.21 & $0.57-2.58$ & 0.624 & & & \\
\hline Pathologic T stage (T1) & 1.18 & $0.86-1.60$ & 0.302 & & & \\
\hline Pyuria (more than W5) & 1.47 & $1.08-2.00$ & 0.013 & 1.31 & $0.95-1.80$ & 0.095 \\
\hline Large tumour & 1.51 & $1.11-2.06$ & 0.009 & 1.36 & $0.98-1.87$ & 0.063 \\
\hline Multiple tumour & 1.59 & $1.13-2.24$ & 0.008 & 1.51 & $1.07-2.15$ & 0.019 \\
\hline Concomitant CIS & 0.97 & $0.68-1.41$ & 0.902 & & & \\
\hline
\end{tabular}

Through the univariate analysis performed using the Cox proportional hazards regression model, with respect to PFS, pathological T1 (HR: 3.33, 95\% CI: 1.02-10.89, $p=0.046$ ) and the presence of pyuria (HR: $3.52,95 \%$ CI: $1.08-11.44, p=0.036$ ) were found to be statistically significant. The multivariate analysis using the Cox proportional hazards regression model showed that the presence of pyuria was the only significant prognostic marker for PFS (HR: 4.51, 95\% CI: 1.22-16.66, $p=0.024$ ) (Table 4).

Table 4. Univariate and multivariable cox proportional hazards regression for progression-free survival.

\begin{tabular}{|c|c|c|c|c|c|c|}
\hline \multirow[b]{2}{*}{ Variables } & \multicolumn{3}{|c|}{ Univariate } & \multicolumn{3}{|c|}{ Multivariable } \\
\hline & Hazard Ratio & $\begin{array}{l}\text { Confidence } \\
\text { Interval }\end{array}$ & $p$-Value & Hazard Ratio & $\begin{array}{l}\text { Confidence } \\
\text { Interval }\end{array}$ & $p$-Value \\
\hline Age & & & 0.866 & & & \\
\hline Age $<65$ & Ref. & & & & & \\
\hline $65 \leq$ Age $\leq 75$ & 0.66 & $0.15-2.97$ & & & & \\
\hline Age $>75$ & 0.81 & $0.20-3.25$ & & & & \\
\hline Previous TUR history & 0.64 & $0.21-1.97$ & 0.435 & & & \\
\hline Sex (Female) & 0.49 & $0.06-3.80$ & 0.498 & & & \\
\hline $\begin{array}{l}\text { Previous BCG treatment } \\
\text { history }\end{array}$ & 1.62 & $0.36-7.33$ & 0.529 & & & \\
\hline $\begin{array}{l}\text { Upper Tract Urothelial } \\
\text { Carcinoma history }\end{array}$ & 0.56 & $0.07-4.31$ & 0.578 & & & \\
\hline $\begin{array}{l}\text { BCG dose reduction } \\
\text { (half) }\end{array}$ & 2.40 & $0.31-18.59$ & 0.402 & & & \\
\hline Pathologic T stage (T1) & 3.33 & $1.02-10.89$ & 0.046 & & & 0.157 \\
\hline Pyuria (more than W5) & 3.52 & $1.08-11.44$ & 0.036 & 4.51 & $1.22-16.66$ & 0.024 \\
\hline Large tumour & 2.34 & $0.74-7.38$ & 0.147 & & & \\
\hline Multiple tumour & 6.32 & $0.82-48.93$ & 0.078 & 5.97 & $0.77-46.28$ & 0.087 \\
\hline Concomitant CIS & 2.20 & $0.72-6.72$ & 0.167 & & & \\
\hline
\end{tabular}

\section{Discussion}

In this study, we evaluated the predictive markers of BCG unresponsiveness in NMIBC. In addition to other well-known predictive factors, such as a history of UTUC and the presence of multiple bladder tumours, pyuria is a predictive marker of BCG unresponsiveness. The Kaplan-Meier survival analysis showed a significantly worse RFS 
(33.74 \pm 2.07 months vs. $38.79 \pm 1.51$ months, $p=0.013)$ and PFS (55.40 \pm 0.92 months vs. $56.70 \pm 0.40$ months, $p=0.025$ ) in the pyuria group than in the sterile urine group. The analysis using the Cox proportional hazards model showed that pyuria was a significant prognostic factor for PFS (HR: 4.51, 95\% CI: 1.22-16.66, $p=0.024$ ).

BCG immunotherapy was first used in 1979 for human bladder cancer and is still the most effective adjuvant treatment for managing NMIBC. However, up to $45 \%$ of patients do not respond to BCG immunotherapy within 2 years of initiating treatment [14]. The BCG-unresponsive patients show poorer oncological outcomes than the BCG-effective patients [15]. For this reason, early cystectomy is recommended for BCG-unresponsive patients over repeated BCG treatment [16]. In this study population, the rate of BCG unresponsiveness was 37.6\% (170/453), which is similar to the results of previous studies [14].

Despite their clinical importance, the predictive markers of BCG unresponsiveness have not been adequately studied. Several clinicopathological parameters, including age, sex, tumour recurrence, tumour stage, tumour grade, the presence of carcinoma in situ and tumour multiplicities, are useful for predicting a patient's BCG response [17]. However, BCG immunotherapy is recommended for high-grade, recurrent and multiple NMIBC tumours [2,3]; thus, in most cases, these clinical predictive factors cannot be used in real clinical practice. Recent studies found that urinary cytokine, fluorescent in situ hybridization (FISH) patterns of cytology [18], intra-cellular proteins such as nucleotide-binding oligomerization domain-like receptors (NLRs) [19] and tumour-infiltrating immune cells [20] are important biomarkers of BCG unresponsiveness. However, most of these biomarkers need additional procedures, like PCR, FISH Immunohistochemistry staining or Enzyme-Linked Immunosorbent Assay of a pathologic specimen or urine. In this study, we found that preoperative pyuria is an independent predictive marker of BCG unresponsiveness, which makes it an easy-to-use, cost-effective clinical parameter.

Miyake et al. compared an NMIBC with a history of UTUC cohort with a primary NMIBC cohort for BCG response in a propensity-matched population [21]. They reported that patients with NMIBC with a history of UTUC had a higher risk of bladder cancer recurrence than patients in the control group. A history of UTUC was identified as an independent prognostic factor of intravesical recurrence of urothelial cell carcinoma in a previous study $[22,23]$. These findings suggest that a history of UTUC increases the risk of bladder cancer recurrence or development, which supports this study's finding that a history of UTUC is a predictive marker of BCG response.

In this study, preoperative pyuria was considered as a predictive marker of BCG unresponsiveness and a prognostic marker of PFS. Although the multivariate Cox analysis did not show pyuria to be a significant prognostic factor for RFS, the Kaplan-Meier analysis showed that the pyuria group had a significantly worse RFS compared to the sterile urine group. Several studies have reported preoperative pyuria as a prognostic marker of NMIBC recurrence $[9,24]$. The presence of pyuria was significantly higher in the BCG-unresponsive group than in the BCG-effective group (46.4\% vs. $35.9 \%, p=0.039$ ) in this study, similar to previous reports $[9,24]$. However, these findings should be interpreted very carefully. The difference in the presence of preoperative pyuria was just $10 \%$ between the two groups (BCG unresponsive and BCG effective), suggesting that this finding is not clinically meaningful [25]. Similarly, although we found a statistically significant association between pyuria and PFS in this study, there was only a 1 month difference in the mean PFS between the two groups. Due to the long interval between the preoperative urine laboratory tests and recurrence or progression, preoperative pyuria itself may not have directly affected the oncological outcome of BCG-treated NMIBC. For this reason, we hypothesised that preoperative pyuria reflects disease aggressiveness [26] or a peritumoural inflammatory response [27], which can directly affect a BCG immunotherapy response. Therefore, we carefully considered preoperative pyuria as a predictive marker of BCG unresponsiveness that may indirectly affect RFS or PFS.

This study has several limitations. The definition of pyuria is not objective and varies in the literature $[12,28]$. Moreover, pyuria is associated with numerous conditions such 
as infection, autoimmune disease and TURBT itself [29]; thus, we need to interpret the results of this study cautiously. Despite these limitations, we successfully analysed the predictive markers of BCG unresponsiveness. To the best of our knowledge, this study investigated BCG unresponsiveness using the largest dataset to date, which was taken from a prospective cohort of patients with NMIBC. We identified a novel predictive marker of BCG unresponsiveness, namely, the presence of preoperative pyuria, and this finding was confirmed by survival analysis. A well-designed study with a more clearly selected cohort is needed to evaluate the prognostic impact of preoperative pyuria on RFS and PFS in patients with NMIBC.

In conclusion, the presence of pyuria, a history of UTUC and multiple tumours are predictive markers of BCG unresponsiveness. The preoperative pyuria group showed shorter RFS and PFS than the control group. The multivariate analysis performed using a Cox regression model showed that pyuria was a prognostic factor for PFS. For patients with NMIBC who have preoperative pyuria, treatment using BCG should be considered cautiously.

Author Contributions: Conceptualization, J.S. and J.H.K.; Methodology and Formal Analysis, J.S.; Resources and Data Curation, H.D.Y. and C.W.J.; Writing — Original Draft Preparation, J.S.; WritingReview and Editing, C.K. and H.H.K.; Visualization, J.S.; Supervision, C.W.J., C.K., H.H.K. and J.H.K. All authors have read and agreed to the published version of the manuscript.

Funding: This research received no external funding.

Institutional Review Board Statement: This study was approved by the SNUH Institutional Review Board (SNUH IRB).

Informed Consent Statement: Informed consent for the academic use of their clinical data was obtained from each patient at the time of their enrolment in the prospective registry (IRB No.: H-1506-122-682).

Data Availability Statement: The data presented in this study are available on request from the corresponding author. The data are not publicly available due to patient privacy.

Conflicts of Interest: The authors declare that the research was conducted in the absence of any commercial or financial relationships that could be construed as a potential conflict of interest.

\section{References}

1. Bray, F.; Ferlay, J.; Soerjomataram, I.; Siegel, R.L.; Torre, L.A.; Jemal, A. Global cancer statistics 2018: GLOBOCAN estimates of incidence and mortality worldwide for 36 cancers in 185 countries. CA Cancer J. Clin. 2018, 68, 394-424. [CrossRef]

2. Babjuk, M.; Burger, M.; Compérat, E.M.; Gontero, P.; Mostafid, A.H.; Palou, J.; van Rhijn, B.W.G.; Rouprêt, M.; Shariat, S.F.; Sylvester, R.; et al. European Association of Urology Guidelines on Non-muscle-invasive Bladder Cancer (TaT1 and Carcinoma In Situ)—2019 Update. Eur. Urol. 2019, 76, 639-657. [CrossRef] [PubMed]

3. Chang, S.S.; Boorjian, S.A.; Chou, R.; Clark, P.E.; Daneshmand, S.; Konety, B.R.; Pruthi, R.; Quale, D.Z.; Ritch, C.R.; Seigne, J.D.; et al. Diagnosis and Treatment of Non-Muscle Invasive Bladder Cancer: AUA/SUO Guideline. J. Urol. 2016, 196, 1021-1029. [CrossRef] [PubMed]

4. Kamat, A.M.; Sylvester, R.J.; Böhle, A.; Palou, J.; Lamm, D.L.; Brausi, M.; Soloway, M.; Persad, R.; Buckley, R.; Colombel, M.; et al. Definitions, end points, and clinical trial designs for non-muscle-invasive bladder cancer: Recommendations from the International Bladder Cancer Group. J. Clin. Oncol. 2016, 34, 1935-1944. [CrossRef] [PubMed]

5. Li, R.; Kamat, A.M. Predictors of Response to Intravesical Therapy. Urol. Clin. N. Am. 2020, 47, 23-33. [CrossRef] [PubMed]

6. Pettenati, C.; Ingersoll, M.A. Mechanisms of BCG immunotherapy and its outlook for bladder cancer. Nat. Rev. Urol. 2018, 15, 615-625. [CrossRef] [PubMed]

7. Suh, J.; Jung, J.H.; Jeong, C.W.; Kwak, C.; Kim, H.H.; Ku, J.H. Clinical Significance of Pre-treated Neutrophil-Lymphocyte Ratio in the Management of Urothelial Carcinoma: A Systemic Review and Meta-Analysis. Front. Oncol. 2019, 9, 1365. [CrossRef] [PubMed]

8. Li, D.Y.; Hao, X.Y.; Ma, T.M.; Dai, H.X.; Song, Y.S. The Prognostic Value of Platelet-to-Lymphocyte Ratio in Urological Cancers: A Meta-Analysis. Sci. Rep. 2017, 7, 15387. [CrossRef]

9. Satake, N.; Ohno, Y.; Nakashima, J.; Ohori, M.; Tachibana, M. Prognostic value of preoperative pyuria in patients with nonmuscle-invasive bladder cancer. Int. J. Urol. 2015, 22, 645-649. [CrossRef] 
10. Jeong, C.W.; Suh, J.; Yuk, H.D.; Tae, B.S.; Kim, M.; Keam, B.; Kim, J.H.; Kim, S.Y.; Cho, J.Y.; Kim, S.H.; et al. Establishment of the Seoul National University Prospectively Enrolled Registry for Genitourinary Cancer (SUPER-GUC): A prospective, multidisciplinary, bio-bank linked cohort and research platform. Investig. Clin. Urol. 2019, 60, 235. [CrossRef]

11. Suh, J.; Moon, K.C.; Jung, J.H.; Lee, J.; Song, W.H.; Kang, Y.J.; Jeong, C.W.; Kwak, C.; Kim, H.H.; Ku, J.H. BCG instillation versus radical cystectomy for high-risk NMIBC with squamous/glandular histologic variants. Sci. Rep. 2019, 9, 15268. [CrossRef]

12. Jeon, B.J.; Tae, B.S.; Choi, H.; Bae, J.H.; Kim, J.W.; Park, H.S.; Park, J.Y. Preoperative sterile pyuria as a prognostic biomarker for intravesical recurrence in upper urinary tract urothelial carcinoma. Investig. Clin. Urol. 2020, 61, 51-58. [CrossRef]

13. Virtanen, P.; Gommers, R.; Oliphant, T.E.; Haberland, M.; Reddy, T.; Cournapeau, D.; Burovski, E.; Peterson, P.; Weckesser, W.; Bright, J.; et al. SciPy 1.0: Fundamental algorithms for scientific computing in Python. Nat. Methods 2020, 17, 261-272. [CrossRef]

14. Nepple, K.G.; Lightfoot, A.J.; Rosevear, H.M.; O’Donnell, M.A.; Lamm, D.L. Bacillus Calmette-Guréin with or without interferon $\alpha-2 b$ and megadose versus recommended daily allowance vitamins during induction and maintenance intravesical treatment of nonmuscle invasive bladder cancer. J. Urol. 2010, 184, 1915-1919. [CrossRef]

15. Li, R.; Tabayoyong, W.B.; Guo, C.C.; González, G.M.N.; Navai, N.; Grossman, H.B.; Dinney, C.P.; Kamat, A.M. Prognostic Implication of the United States Food and Drug Administration-defined BCG-unresponsive Disease. Eur. Urol. 2019, 75, 8-10. [CrossRef]

16. Kikuchi, E.; Hayakawa, N.; Fukumoto, K.; Shigeta, K.; Matsumoto, K. Bacillus Calmette-Guérin-unresponsive non-muscleinvasive bladder cancer: Its definition and future therapeutic strategies. Int. J. Urol. 2020, 27, 108-116. [CrossRef] [PubMed]

17. Kamat, A.M.; Li, R.; O’Donnell, M.A.; Black, P.C.; Roupret, M.; Catto, J.W.; Comperat, E.; Ingersoll, M.A.; Witjes, W.P.; McConkey, D.J.; et al. Predicting Response to Intravesical Bacillus Calmette-Guérin Immunotherapy: Are We There Yet? A Systematic Review. Eur. Urol. 2018, 73, 738-748. [CrossRef] [PubMed]

18. Faba, Ó.R.; Pisano, F.; Krajewski, W.; Breda, A.; Palou, J. Salvage Therapies for Non-muscle-invasive Bladder Cancer: Who Will Respond to Bacillus Calmette-Guérin? Predictors and Nomograms. Urol. Clin. N. Am. 2020, 47, 5-13. [CrossRef] [PubMed]

19. Poli, G.; Cochetti, G.; Boni, A.; Egidi, M.G.; Brancorsini, S.; Mearini, E. Characterization of inflammasome-related genes in urine sediments of patients receiving intravesical BCG therapy. Urol. Oncol. Semin. Orig. Investig. 2017, 35, 674.e19-674.e24. [CrossRef] [PubMed]

20. Kardoust Parizi, M.; Shariat, S.F.; Margulis, V.; Mori, K.; Lotan, Y. Value of tumour-infiltrating immune cells in predicting response to intravesical BCG in patients with non-muscle-invasive bladder cancer: A systematic review and meta-analysis. BJU Int. 2021, 127, 617-625. [CrossRef] [PubMed]

21. Miyake, M.; Tatsumi, Y.; Matsumoto, H.; Nagao, K.; Matsuyama, H.; Inamoto, T.; Azuma, H.; Yasumoto, H.; Shiina, H.; Fujimoto, K. Outcomes of subsequent non-muscle-invasive bladder cancer treated with intravesical Bacillus Calmette-Guérin after radical nephroureterectomy for upper urinary tract urothelial carcinoma. BJU Int. 2018, 121, 764-773. [CrossRef] [PubMed]

22. Elawdy, M.M.; Osman, Y.; Taha, D.E.; Zahran, M.H.; El-Halwagy, S.; Garba, M.; El-Harraz, A.M. Risk factors and prognosis of intravesical recurrence after surgical management of upper tract urothelial carcinoma: A 30-year single centre experience. Arab J. Urol. 2017, 15, 216-222. [CrossRef]

23. Kim, H.S.; Jeong, C.W.; Kwak, C.; Kim, H.H.; Ku, J.H. Novel nomograms to predict recurrence and progression in primary non-muscle-invasive bladder cancer: Validation of predictive efficacy in comparison with European Organization of Research and Treatment of Cancer scoring system. World J. Urol. 2019, 37, 1867-1877. [CrossRef]

24. Azuma, T.; Nagase, Y.; Oshi, M. Pyuria predicts poor prognosis in patients with non-muscle-invasive bladder cancer. Clin. Genitourin. Cancer 2013, 11, 331-336. [CrossRef]

25. Bhardwaj, S.S.; Camacho, F.; Derrow, A.; Fleischer, A.B.; Feldman, S.R. Statistical Significance and Clinical Relevance. Arch. Dermatol. 2004, 140, 1520-1523. [CrossRef]

26. Poletajew, S.; Gajewska, D.; Kaczmarek, K.; Krajewski, W.; Łykowski, M.; Sondka-Migdalska, J.; Borowik, M.; Buraczyński, P.; Dziegała, M.; Przudzik, M.; et al. Preoperative pyuria predicts the presence of high-grade bladder carcinoma in patients with bladder tumors. Cent. Eur. J. Urol. 2020, 73, 423. [CrossRef]

27. Sui, X.; Lei, L.; Chen, L.; Xie, T.; Li, X. Inflammatory microenvironment in the initiation and progression of bladder cancer. Oncotarget 2017, 8, 93279-93294. [CrossRef] [PubMed]

28. Sato, G.; Yoshida, T.; Yanishi, M.; Saito, R.; Murota, T.; Kawa, G.; Kinoshita, H.; Matsuda, T. Preoperative Pyuria Predicts for Intravesical Recurrence in Patients With Urothelial Carcinoma of the Upper Urinary Tract After Radical Nephroureterectomy Without a History of Bladder Cancer. Clin. Genitourin. Cancer 2020, 18, e167-e173. [CrossRef]

29. Kim, B.S.; Tae, B.S.; Ku, J.H.; Kwak, C.; Kim, H.H.; Jeong, C.W. Rate and association of lower urinary tract infection with recurrence after transurethral resection of bladder tumor. Investig. Clin. Urol. 2018, 59, 10-17. [CrossRef] [PubMed] 